\title{
Adsorption of Xyloglucan onto Thin Films of Cellulose Nanocrystals and Amorphous Cellulose: Film Thickness Effects
}

\author{
Joshua D. Kittle, ${ }^{*}{ }^{\dagger}$ Chen Qian, ${ }^{\ddagger}$ Emma Edgar, ${ }^{\ddagger}$ Maren Roman, ${ }^{\S}$ and Alan R. Esker ${ }^{\ddagger}$ \\ ${ }^{\dagger}$ Department of Chemistry \& Chemistry Research Center, United States Air Force Academy, Colorado Springs, Colorado 80840, \\ United States \\ ${ }^{\ddagger}$ Department of Chemistry and ${ }^{\S}$ Department of Wood Science and Forest Products, Virginia Tech, Blacksburg, Virginia 24061, \\ United States
}

\section{Supporting Information}

ABSTRACT: The interaction between cellulose and hemicelluloses is of fundamental importance for understanding the molecular architecture of plant cell walls. Adsorption of xyloglucan $(\mathrm{XG})$ onto regenerated cellulose (RC), sulfated cellulose nanocrystal (s-CNC), and desulfated cellulose nanocrystal (d-CNC) films was studied by quartz crystal microbalance with dissipation monitoring, surface plasmon resonance, and atomic force microscopy. The amount of XG adsorbed onto different cellulose substrates increased in the order $\mathrm{RC}<\mathrm{s}-\mathrm{CNC}<\mathrm{d}-\mathrm{CNC}$. The adsorption of XG onto RC films was independent of film thickness (d), whereas XG adsorption was weakly dependent on $d$ for s-CNC films and strongly dependent on $d$ for d-CNC films. However, approximately the same amount of XG adsorbed onto "monolayer-thin" films of RC, s-CNC, and d-CNC. These results suggest that the morphology and surface charge of the cellulose substrate played a limited role in XG adsorption and highlight the importance of film thickness of cellulose nanocrystalline films to XG adsorption.

\section{INTRODUCTION}

Understanding the structure and synthesis of natural systems is of fundamental interest, particularly for those seeking renewable sources of energy and functional materials. ${ }^{1}$ Resources from plants, such as cellulose and, to a lesser extent, xyloglucan (XG), have already found widespread use in the paper, textile, and food industries. ${ }^{2,3}$ A deeper comprehension of the primary cell wall of plants, to include the interactions of cellulose with other cell wall polysaccharides such as XG, could facilitate the extraction and use of these renewable resources. ${ }^{1,4}$

The primary cell wall of wood and flowering plants is a thin layer $(50-200 \mathrm{~nm})$ composed of cellulose, hemicelluloses, and pectin. Cellulose, constituting $20-30 \%$ of the solid mass of the cell wall, is arranged as crystalline microfibrils with diameters of $\sim 4 \mathrm{~nm}$ and degrees of polymerization ranging from 200 to 4500 , although amorphous cellulose domains are also present. Hemicelluloses, which account for $20-30 \%$ of the solid cell wall mass, network the cellulose microfibrils through either direct or indirect linkages. XG is typically the most abundant hemicellulose in the primary cell wall, converting the cellulose network into a more elastomeric system. Pectins cross-link with other pectins or $\mathrm{Ca}^{2+}$ ions to form a separate network, with the degree of acetylation along the pectin chains affecting the water content and porosity of the wall. Additionally, primary cell walls of these plants contain at least $70 \%$ water by mass, as well as soluble salts and oftentimes glycoproteins. ${ }^{5,6}$

\section{Xyloglucan Adsorption to Model Cellulose Thin Films}
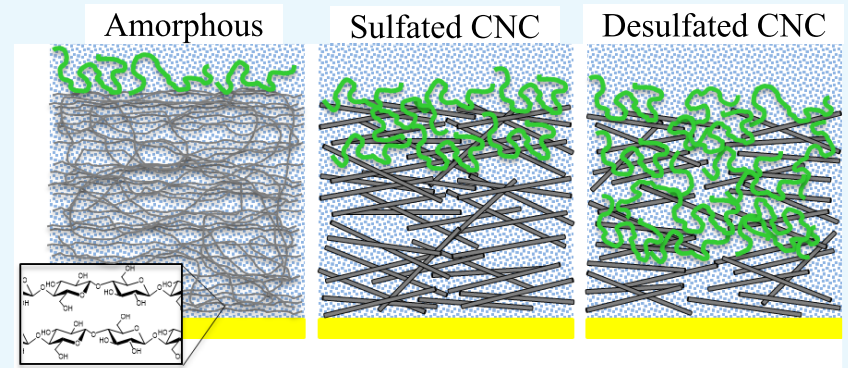

Although XG significantly alters the mechanical properties of the cellulose network of wood and flowering plants, the nature of the interactions between XG and cellulose is not fully understood. ${ }^{7}$ In brief, XG has been proposed to cross-link cellulose microfibrils, either via physical entrapment of a XG chain end within a cellulose microfibril and noncovalent (e.g., hydrogen-bonding) interactions with the surface of an adjacent microfibril, or via purely noncovalent interactions between XG and multiple microfibril surfaces. ${ }^{8,9}$ An alternative model suggests that XG does not link cellulose microfibrils together, but rather links the cellulose microfibrils to the pectic network. In this model, one XG chain end noncovalently interacts with a microfibril, whereas the rest of the chain interacts with pectin, either via covalent or noncovalent linkages. ${ }^{10,11}$ A more recent model proposed on the basis of NMR studies suggests that pectin forms noncovalent cross-links with cellulose microfibrils, XG intercalates between adjacent microfibrils, and pectin covalently cross-links with XG. ${ }^{12}$ Regardless of the means of interaction, the binding of $X G$ to cellulose is a principle feature of the primary cell wall of wood and flowering plants.

Due to the complexity of the cell wall and the difficulty in studying XG-cellulose interactions in situ, several groups have

Received: July 23, 2018

Accepted: October 12, 2018

Published: October 25, 2018 
extracted cellulose and XG from various sources to examine the binding and adsorption behavior between these materials. ${ }^{8,13-20}$ It should be noted that many studies in the literature, including that of this work, use XG from tamarind seeds. This XG source is a storage hemicellulose that differs in sugar side-chain composition, acetylation, and size from XG found in the primary cell wall of woods and flowering plants. $^{21,22}$ Further, the source and material processing of cellulose can alter the physical properties of the surface (e.g., hydrophobicity), also affecting hemicellulose interaction with cellulose. ${ }^{21,23}$ Collectively, studies haves shown that differences in $\mathrm{XG}$ composition and structure, as well as the model cellulose surface, can significantly influence hemicellulosecellulose adsorption. ${ }^{21}$ Regardless, adsorption studies of model hemicelluloses to model cellulose thin films remains an important area of research in understanding both plant cell walls and uses of these materials.

The reported XG adsorption onto cellulose of varied mesostructures ranged from $0.4-27 \mathrm{mg} \cdot \mathrm{m}^{-2} \cdot{ }^{13,16,18}$ This disparity in the reported values may stem from differences in accessible cellulose surface area, as stated by several works. $^{13-15,20}$ Further, the kinetics of XG adsorption can result in variable $\mathrm{XG}$ adsorption based on the experimental conditions. $^{24,25}$ The surface charge of the cellulose may also play a role in $\mathrm{XG}$ adsorption, though the literature shows somewhat conflicting results as to whether charge limits, enhances, or does not affect the XG adsorption to a charged cellulose surface. ${ }^{16-18}$ Although the different molecular weights of the various XG samples used in these studies likely contributes to the significant discrepancy between the reported values for $\mathrm{XG}$ adsorption to cellulose, ${ }^{19}$ lingering questions remain regarding how cellulose morphology, accessible surface area, and charge affect XG adsorption.

The aim of this work was to further investigate the role of model cellulose mesostructure, charge effects, and thin film thickness on the adsorption of XG. The cellulose substrates used in this work were thin films of amorphous regenerated cellulose (RC), ${ }^{26,27}$ sulfated cellulose nanocrystals (s-CNC) containing an anionic surface charge, ${ }^{28,29}$ and desulfated cellulose nanocrystals (d-CNC) containing no charge on the cellulose surface. ${ }^{30}$ Previous studies of RC thin films have determined that spin-coated RC films are essentially amorphous and, while these films swell considerably in water, adsorbates with a radius of gyration $\left(R_{\mathrm{g}}\right)$ as small as 4 $\mathrm{nm}$ were confined to the surface and did not penetrate into the film. ${ }^{27,31,32}$ Previous studies of cellulose nanocrystalline thin films spin-coated from aqueous suspensions have shown than s-CNC and d-CNC are essentially cellulose I (e.g., native crystalline cellulose) with a crystallinity of $\sim 87 \% .^{29,33,34}$ As opposed to RC films, s-CNC and d-CNC films are quite porous to both water and small adsorbates $\left(R_{\mathrm{g}} \sim 4 \mathrm{~nm}\right)$ and the accessible cellulose surface area is proportional to the thickness of the film for small adsorbates. ${ }^{32}$

Because RC, s-CNC, and d-CNC films have varied morphology, surface charge, and accessible surface area, these cellulose substrates are ideally suited for studying how these parameters affect XG adsorption. Consequently, adsorption isotherms for $\mathrm{XG}$ from tamarind onto amorphous $\mathrm{RC}$, sulfated nanocrystalline s-CNC, and desulfated nanocrystalline d-CNC were measured using quartz crystal microbalance with dissipation monitoring (QCM-D) and surface plasmon resonance (SPR). These two complimentary techniques also permit the estimation of the water content of the adsorbed XG layer while allowing inferences about how the various cellulose substrates affect the conformation of the adsorbed XG. Additionally, the effect of accessible surface area of XG adsorption was probed by generating cellulose films of varied thickness $(d)$. Even though specific values of surface area are only known for $\mathrm{RC}$, it is known that the accessible surface areas of s-CNC and d-CNC are directly proportional to the film thickness. ${ }^{32}$ Collectively, this information is expected to aid in selecting appropriate cellulose substrates for studies aimed at investigating interactions between cellulose and other biopolymers, as well as identifying materials for candidates in biomimetic cell wall composites.

\section{RESULTS AND DISCUSSION}

Before determining the maximum XG adsorption onto the $\mathrm{RC}$, s-CNC, and d-CNC model cellulose surfaces via QCM-D and SPR adsorption isotherms, the effect of increasing cellulose film thickness on the quantity of XG adsorbed was first investigated. As previously noted, there is significant disparity in the literature regarding how much XG adsorbs to cellulose and to what extent cellulose morphology, surface charge, and accessible surface area influence XG adsorption. ${ }^{13-20}$ Whereas traditional bulk measurements of porosity in the gas phase would have little relevance to ultrathin films of hydrophilic polymers in aqueous media, changing the thickness of a porous thin film is a viable strategy for observing the effect of increasing surface area on adsorption. ${ }^{32}$ Thus, by examining the adsorption of XG from a single-concentration solution $\left(100 \mathrm{mg} \cdot \mathrm{L}^{-1}\right)$ onto three different model cellulose surfaces, each with varied crystallinity and surface charge, at a range of film thicknesses, the effects of cellulose morphology, surface charge, and surface area on XG adsorption were determined.

As shown in Figure 1, the XG surface excess for RC films was independent of film thickness and equal to $0.63 \pm 0.05$

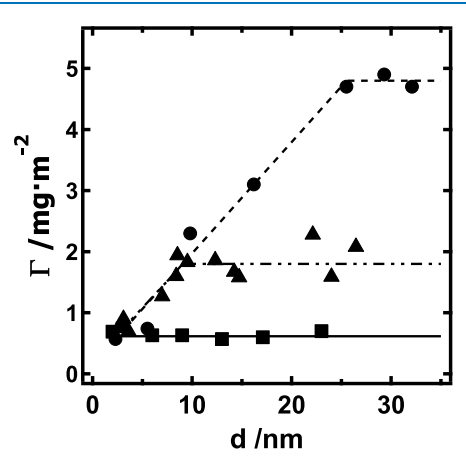

Figure 1. Surface excess $\left(\Gamma_{\mathrm{SPR}}\right)$ of XG versus cellulose film thickness (d) for XG adsorbed onto RC $(\boldsymbol{\square},--)$, s-CNC $(\boldsymbol{\Lambda},-\cdots)$, and d$\mathrm{CNC}(\bullet,--)$ films after $2 \mathrm{~h}$ of exposure to a $100 \mathrm{mg} \cdot \mathrm{L}^{-1} \mathrm{XG}$ solution. Average-value trend lines are provided as a guide to the eye.

$\mathrm{mg} \cdot \mathrm{m}^{-2}$. This result indicates that XG was confined to the RC surface, similar to a previous study of cellulose adsorption to RC. ${ }^{32}$ For s-CNC and d-CNC films, the data indicated two regimes, a film-thickness-dependent and a film-thicknessindependent regime. For both s-CNC and d-CNC films in the thickness-dependent regime, a linear fit of the data had a slope of $0.19 \pm 0.03 \mathrm{mg} \cdot \mathrm{m}^{-2} \cdot \mathrm{nm}^{-1}$. In the thicknessindependent regime, s-CNC and $\mathrm{d}-\mathrm{CNC}$ had XG surface excess values of $1.9 \pm 0.2$ and $4.8 \pm 0.1 \mathrm{mg} \cdot \mathrm{m}^{-2}$, respectively. Note, however, that as the film thickness approached a cellulose "monolayer" $(d \rightarrow 0)$, the XG adsorption onto RC, s- 
$\mathrm{CNC}$, and d-CNC all approached a similar value $\left(\Gamma_{\mathrm{SPR}} \sim 0.7\right.$ $\left.\mathrm{mg} \cdot \mathrm{m}^{-2}\right)$. Control data for XG adsorbed onto gold and onto the self-assembled monolayer-coated gold substrates yielded $\Gamma_{\mathrm{SPR}}$ of $0.37 \pm 0.06$ and $0.28 \pm 0.06 \mathrm{mg} \cdot \mathrm{m}^{-2}$, respectively. Collectively, the data from Figure 1 suggests that cellulose surface charge and morphology play a limited role in XG adsorption, whereas accessible surface area of the thin film significantly affects the measured XG adsorption, in line with other studies.

Regarding surface charge effects, the result of a single slope in the thickness-dependent regime for s-CNC and d-CNC indicates that the surface charge on s-CNC has an insignificant effect on adsorption affinity of XG for the cellulose surface. That XG adsorption onto each model cellulose surface all approach the same surface excess value as the film thickness approaches a nonporous monolayer further supports the conclusion that the anionic surface of s-CNC must not significantly inhibit or promote $\mathrm{XG}$ adsorption. This conclusion is similar to a previous colorimetry study of $\mathrm{XG}$ binding onto s-CNC that observed that the presence of s-CNC sulfate groups had no detectable effect on XG binding. ${ }^{17}$

Likewise, the morphology of the cellulose substrate does not seem to significantly contribute to the observed differences in maximum XG adsorbed onto RC, s-CNC, and d-CNC films. As is evident from Figure 1, XG adsorption onto amorphous RC films and crystalline s-CNC and d-CNC films both approach the same value $\left(\sim 0.7 \mathrm{mg} \cdot \mathrm{m}^{-2}\right)$ as the thickness of the cellulose substrate approaches a monolayer. This lack of preferential binding of XG onto different cellulose morphologies has been proposed in the literature and is not so surprising when considering that at the crystal surface, cellulose chains have disrupted hydrogen-bonding pairs and a structure that deviates from that of cellulose chains in the middle of the crystal lattice. ${ }^{17,20,35,36}$ In fact, surface chains of crystalline cellulose have been considered essentially amorphous. ${ }^{37}$

However, as shown in other studies, the accessible surface area of cellulose thin films significantly affected the measured XG adsorption and should be quantified to ensure the measurement of adsorption isotherms in the thicknessindependent regime for the cellulose surface used. ${ }^{13-15}$ As expected, the XG adsorption to the RC films did not depend on film thickness, indicating XG was confined to the surface. However, for the porous, crystalline s-CNC and d-CNC films, the film-thickness-dependent regime for $\mathrm{XG}$ adsorption suggests that XG entered the s-CNC and d-CNC films, increasing the available surface area for binding interactions and consistent with similar work with cellulose nanocrystals. $^{20,32,38}$ Though XG adsorption onto d-CNC surfaces was greater than that onto s-CNC surfaces by nearly a factor of 2 , this observation likely stems from differences in pore size between $\mathrm{d}-\mathrm{CNC}$ and $\mathrm{s}-\mathrm{CNC}$ films rather than a difference in $\mathrm{XG} /$ cellulose interaction caused by electrostatic effects. ${ }^{29,32}$ The porosity of cellulose nanocrystalline thin films is well established. A previous study of cellulase adsorption to d-CNC and s-CNC films noted nearly identical adsorption of cellulase to these substrates. ${ }^{32}$ The radius of gyration of XG in solution has been measured to be $\sim 120 \mathrm{~nm}(\sim 800 \mathrm{kDa})$, whereas that of cellulase is $\sim 4 \mathrm{~nm} .{ }^{39,40}$ Coupled with the result of similar $\mathrm{XG}$ adsorption onto a cellulose monolayer for s-CNC and d$\mathrm{CNC}$, it is likely that s-CNC films have smaller pores than dCNC films and that these larger XG molecules (relative to cellulase) are not able to enter as deeply into the s-CNC film. Smaller pore sizes for s-CNC films relative to d-CNC films are expected, as d-CNC colloidal suspensions are known to form larger aggregates in suspension and form thicker, rougher films than s-CNC when spin-coated under identical conditions. ${ }^{30,32}$

To further investigate the differences in accessible surface area between the three cellulose model substrates, the viscoelasticity of the $\mathrm{XG} /$ cellulose substrate was measured via QCM-D. As an acoustic technique, the QCM-D is sensitive to changes in density and viscosity of the surrounding medium. ${ }^{41}$ An indication of the viscous nature of an adsorbed layer is provided by changes in dissipation $(D)$

$$
\Delta D=\frac{E_{\text {dissipated }}}{2 \pi E_{\text {stored }}}
$$

where $E_{\text {stored }}$ is the energy stored in the sensor crystal and $E_{\text {dissipated }}$ is the energy dissipated by the viscous nature of the surrounding medium. An increase in $\Delta D$ indicates the addition of a more viscous medium (e.g., swelling), whereas a decrease indicates a change to a more rigid environment (e.g., from networking or release of solvent). ${ }^{41-44}$

As shown in Figure 2A, $\Delta D$ increased slightly for both low and high concentrations when XG adsorbed onto RC, s-CNC,
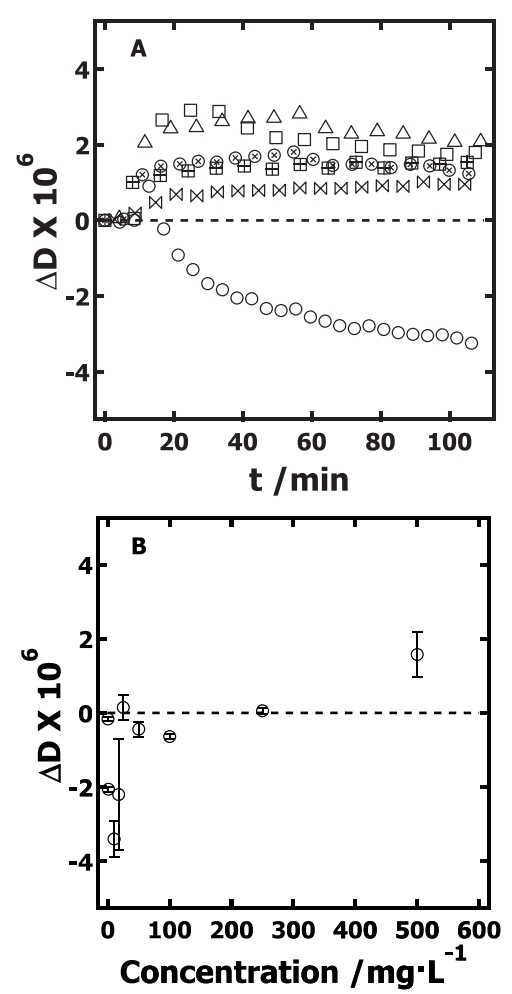

Figure 2. (A) Representative plots of $\Delta D$ versus time $(t)$ (5th overtone) for XG adsorbed onto RC ( $⿴ 囗 十 10 \mathrm{mg} \cdot \mathrm{L}^{-1} \mathrm{XG}, \square 500 \mathrm{mg}$. $\left.\mathrm{L}^{-1} \mathrm{XG}\right)$, s-CNC $\left(\bowtie 10 \mathrm{mg} \cdot \mathrm{L}^{-1} \mathrm{XG}, \Delta 500 \mathrm{mg} \cdot \mathrm{L}^{-1} \mathrm{XG}\right)$, and d-CNC (○ $10 \mathrm{mg} \cdot \mathrm{L}^{-1} \mathrm{XG}, \otimes 500 \mathrm{mg} \cdot \mathrm{L}^{-1} \mathrm{XG}$ ) films measured in the cellulose-film-thickness-independent regime $\left(d_{\mathrm{RC}}=22 \mathrm{~nm}, d_{\mathrm{s}-\mathrm{CNC}}=\right.$ $26 \mathrm{~nm}, d_{\mathrm{d}-\mathrm{CNC}}=30 \mathrm{~nm}$ ). (B) $\Delta D$ versus concentration for XG adsorbed onto d-CNC films. The zero-point $\Delta D$ is provided as a reference (---).

and $\mathrm{d}-\mathrm{CNC}$, the exception being when $\mathrm{XG}$ adsorbed onto dCNC films from low-concentration solutions. For $\mathrm{XG}$ adsorption onto d-CNC films, a crossover from negative to positive $\Delta D$ occurs at $\sim 250 \mathrm{mg} \cdot \mathrm{L}^{-1}$ (Figure $2 \mathrm{~B}$ ). Thus, for RC and $\mathrm{s}-\mathrm{CNC}$ films, the dissipation increased with $\mathrm{XG}$ adsorption, consistent with adsorption of a floppy, swollen 
film at the surface. ${ }^{41}$ However, the dissipation initially decreased at low concentrations of XG adsorption onto the d-CNC films. A dissipation decrease is indicative of a decrease in the viscoelasticity of the system (e.g., the system becomes more rigid). ${ }^{41}$ The crossover from negative to positive dissipation upon increasing adsorption has previously been attributed to the removal of water from the system. ${ }^{42-44}$

As discussed in greater detail later in this work, the average water content for XG films adsorbed onto the three cellulose substrates increased in the order of d-CNC $(38 \pm 6 \%)<s$ $\mathrm{CNC}(54 \pm 9 \%)<\mathrm{RC}(81 \pm 3 \%)$. This trend is reasonable for XG penetrating into the porous s-CNC and d-CNC films. Unlike XG adsorbed at the surface where each XG molecule added to the surface brings new coupled water to the film, XG penetrating into the film must displace water already coupled to the film ( $80 \%$ by volume), leading to smaller apparent water contents. $^{32}$ In fact, a recent study shows that the driving mechanism for XG adsorption onto cellulose is the entropic release of water caused by XG displacement. ${ }^{20}$

Considering that before XG adsorption, the porous d-CNC films contain significant water content between the rodlike nanocrystals of the thin film and that Figure 1 clearly illustrates that $\mathrm{d}-\mathrm{CNC}$ films are porous to $\mathrm{XG},{ }^{32}$ it is reasonable to suggest that at low XG concentrations, the XG enters the $\mathrm{d}$ CNC film, displacing water and resulting in the observed dissipation decrease. As the XG concentration increases and the $\mathrm{d}$-CNC film saturates, the XG adsorbs to the surface, forming a floppy swollen film (similar to the case for RC and s$\mathrm{CNC}$ ) and leading to a dissipation increase. This dissipation increase for $\mathrm{XG}$ adsorption at higher concentrations onto dCNC films may also be a function of swelling within the dCNC film caused by flexible tethering of nanocrystals by the $\mathrm{XG}$, similar to observations made by Cerclier et al. ${ }^{18}$ Although these effects might also be expected for XG adsorption to the porous s-CNC films, it should be noted that the thickness dependence of $\mathrm{XG}$ adsorption occurred over a smaller range of film thicknesses and the total amount of XG adsorbed onto sCNC was much lower than that for the case of d-CNC.

After determining the film thickness of the independent regime for each model cellulose substrate, adsorption isotherms for $\mathrm{XG}$ onto $\mathrm{RC}, \mathrm{s}-\mathrm{CNC}$, and $\mathrm{d}-\mathrm{CNC}$ were measured in this thickness-independent regime via both QCM-D and SPR (Figure 3). Representative data for each isotherm data point is provided in the Supporting Information (Figure S1). Details of the conversion of the measured QCM$\mathrm{D}$ and SPR data into $\Gamma_{\mathrm{QCM}}$ and $\Gamma_{\mathrm{SPR}}$, respectively, are also provided in the Supporting Information (Table S1). In brief, the Sauerbrey equation was used to convert the scaled frequency change $(\Delta f / n)$ measured by QCM-D into $\Gamma_{\mathrm{QCM}}{ }^{45}$ whereas the equation of de Feijter et al. was used to convert the irreversible change in surface plasmon angle $\left(\theta_{\mathrm{sp}}\right)$ into $\Gamma_{\mathrm{SPR}}$, similar to previous reports. ${ }^{46,47}$ Values of $\Gamma_{\mathrm{QCM}}$ and $\Gamma_{\mathrm{SPR}}$ for XG adsorption onto RC, s-CNC, and d-CNC films were fit by both the Langmuir and Freundlich isotherms, though Figure 3 shows only the model that best fit the data. Parameters for this models are provided in the Supporting Information (Table S2).

As is evident from Figure 3, the amount of $\mathrm{XG}$ adsorbed onto cellulose substrates increased in the order $\mathrm{RC}<\mathrm{s}-\mathrm{CNC}<$ d-CNC for both measurement techniques. Additionally, for each of the three different cellulose substrates, $\Gamma_{\mathrm{QCM}}$ was greater than $\Gamma_{\mathrm{SPR}}$. This is expected, as QCM-D is sensitive to both the adsorbed film, its viscoelastic properties (e.g., rigid or
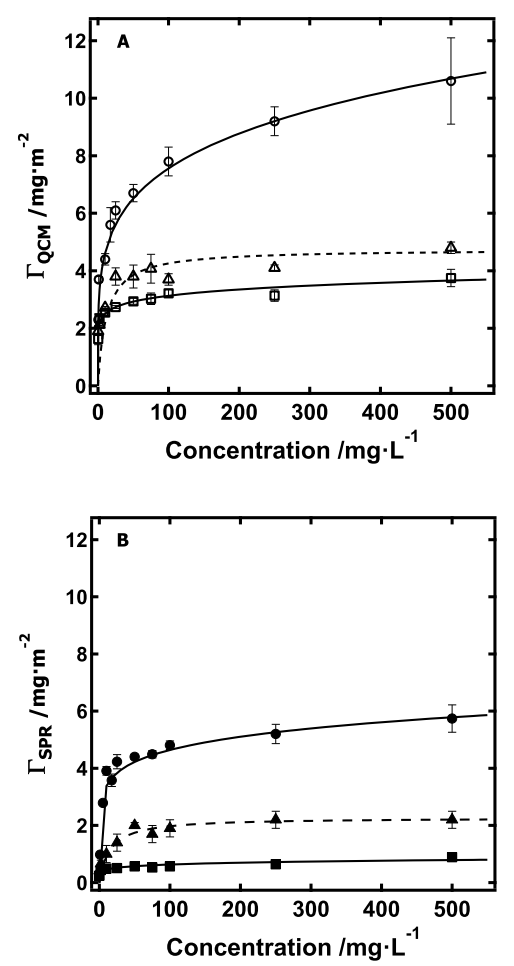

Figure 3. Adsorption isotherms obtained for $\mathrm{XG}$ adsorption via QCM-D for XG onto (A) ( $\square)$ RC $(d=15 \mathrm{~nm}),(\Delta)$ s-CNC $(d=13$ $\mathrm{nm})$, and $(\mathrm{O}) \mathrm{d}-\mathrm{CNC}(d=30 \mathrm{~nm})$ films via QCM-D and (B) onto $(\boldsymbol{\square}) \mathrm{RC},(\boldsymbol{\Delta}) \mathrm{s}-\mathrm{CNC}$, and (-) d-CNC films via SPR. Solid lines represent fits with Freundlich isotherms, whereas dashed lines indicate fits with Langmuir isotherms.

soft), and any water entrapped within the film, ${ }^{48}$ whereas SPR is sensitive only to the adsorbed film. ${ }^{32}$ QCM-D results showed that the maximum $\Gamma$ for XG adsorption onto the three cellulose substrates increased in the order of RC $(3.8 \pm 0.3$ $\left.\mathrm{mg} \cdot \mathrm{m}^{-2}\right)<\mathrm{s}-\mathrm{CNC}\left(4.8 \pm 0.2 \mathrm{mg} \cdot \mathrm{m}^{-2}\right)<\mathrm{d}-\mathrm{CNC}(11 \pm 2 \mathrm{mg}$. $\left.\mathrm{m}^{-2}\right)$. Likewise, SPR results showed that maximum $\Gamma$ for $X G$ adsorbed onto the three cellulose substrates increased in the order of RC $\left(0.9 \pm 0.2 \mathrm{mg} \cdot \mathrm{m}^{-2}\right)<\mathrm{s}-\mathrm{CNC}\left(2.2 \pm 0.3 \mathrm{mg} \cdot \mathrm{m}^{-2}\right)$ $<\mathrm{d}$-CNC $\left(5.7 \pm 0.5 \mathrm{mg} \cdot \mathrm{m}^{-2}\right)$. The maximum surface concentrations $(\Gamma)$ as determined by SPR compare favorably with previous studies of XG adsorption onto cellulose. Literature values for $\Gamma$ range from $0.4-2.2 \mathrm{mg} \cdot \mathrm{m}^{-2}$, which agree within about an order of magnitude of the values determined in this work. ${ }^{13,14,16,20}$ Because the surface area of some cellulose samples from the literature was not studied, direct comparison of XG adsorption data from several previous studies with this work is not possible, especially as this work infers surface area affects from film thickness and morphology rather than via direct measurement. ${ }^{8,17,19}$ Again, as noted, differences in $\Gamma$ stem from variation in cellulose accessibility, ${ }^{13-15,32}$ although variation in molecular weight of the particular XG samples used throughout the literature, as well as the experimentally variable kinetics of adsorption, also contribute to these differences. ${ }^{19,24,25}$

It should also be noted that care must be taken in selecting the appropriate technique to measure adsorption. For example, QCM-D measurements of XG adsorption onto cellulose give significantly higher $\Gamma$ than other methods, as swelling and viscous effects contribute to the response of the instrument. Several QCM-D studies have noted that XG adsorption onto cellulose continually increases for over $12 \mathrm{~h},{ }^{16,18}$ although the 


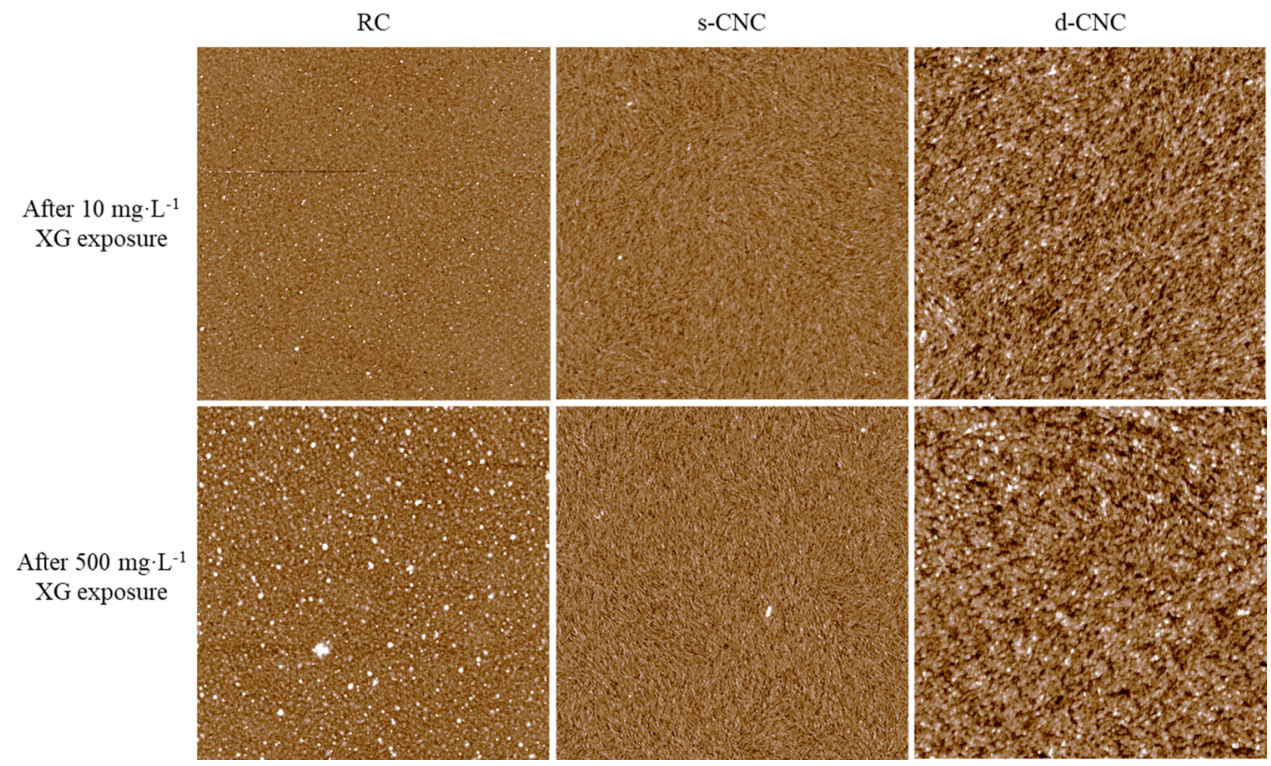

Figure 4. Representative AFM images for bare RC, s-CNC, and d-CNC films exposed to 10 and $500 \mathrm{mg} \cdot \mathrm{L}^{-1} \mathrm{XG}$. The scans are $10 \times 10 \mu \mathrm{m}^{2}$ with a $20 \mathrm{~nm} z$-scale.
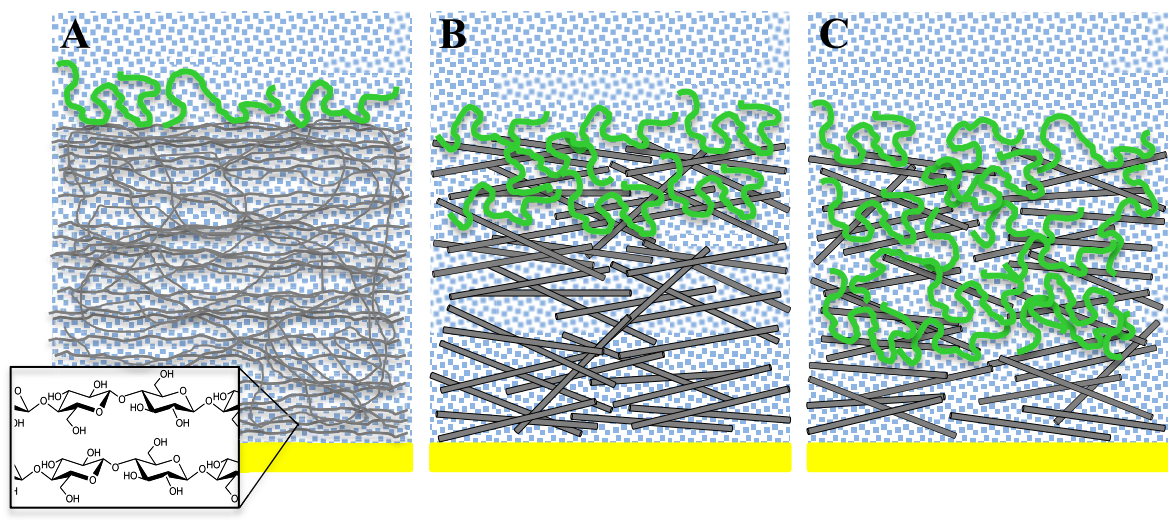

Figure 5. Schematic illustration depicting XG adsorption onto (A) RC films, (B) s-CNC films, and (C) d-CNC films. XG is confined to the surface of RC films, whereas limited sorption occurs in s-CNC and d-CNC films.

SPR data of this work indicated that $2 \mathrm{~h}$ was sufficient to reach maximum irreversible adsorption after rinsing (Figure S1). As noted in the literature, the appearance of long-term XG adsorption via QCM-D may instead be a response driven by a constantly changing conformation of $\mathrm{XG}$ on the surface, highlighting the need for a complimentary technique such as SPR.

The water content associated with $\mathrm{XG}$ adsorbed onto the different cellulose substrates was calculated from the difference in $\Gamma$ as determined by QCM-D and SPR ${ }^{49}$

$$
\% \text { water }=\left(1-\frac{\Gamma_{\mathrm{SPR}}}{\Gamma_{\mathrm{QCM}}}\right) \times 100 \%
$$

$\Gamma_{\mathrm{QCM}}$ and $\Gamma_{\mathrm{SPR}}$ for each concentration greater than $2 \mathrm{mg} \cdot \mathrm{L}^{-1}$ of each cellulose substrate were used to calculate an average water content for the adsorbed XG layer specific to that cellulose substrate. Using this technique, the average water content for $\mathrm{XG}$ films adsorbed onto the three cellulose substrates increased in the order of d-CNC $(38 \pm 6 \%)<\mathrm{s}-\mathrm{CNC}(54 \pm 9 \%)<\mathrm{RC}$ $(81 \pm 3 \%)$. The type of polymer adsorbed to thin cellulose films (e.g., polyelectrolyte versus XG) strongly affects coupled water, as does the type of cellulose surface (e.g., regenerated cellulose versus CNC). For example, polyelectrolyte adsorption onto regenerated cellulose has shown significant coupled water because the polymer is confined to the surface. ${ }^{50}$ Conversely, polyelectrolyte adsorption onto CNC has shown stiffening and water release. ${ }^{16}$ Again, this trend is reasonable for XG penetrating into the porous s-CNC and d-CNC films, where $\mathrm{XG}$ penetrates into the film and displaces water already coupled to the film ( $80 \%$ by volume) in an entropically favored process, leading to smaller apparent water contents. ${ }^{20,32}$

Atomic force microscopy (AFM) images did not show significant differences at the surface after XG adsorption and subsequent drying. Initially, the cellulose films had root mean square $(\mathrm{RMS})$ roughness values of $1.56 \pm 0.01,2.3 \pm 0.3$, and $3.04 \pm 0.04 \mathrm{~nm}$ for $\mathrm{RC}, \mathrm{s}-\mathrm{CNC}$, and $\mathrm{d}-\mathrm{CNC}$ films, respectively. These values indicate the films are relatively smooth, in agreement with several other studies. ${ }^{14,50,51}$ As shown in Figure 4, some XG appears to adsorb to the cellulose surfaces as aggregates, with a greater amount of aggregation present after exposure to higher XG concentration, especially for RC films. The size of the aggregates did not change significantly from low to high concentration, nor did the RMS roughness of the 
films change significantly after XG adsorption (Figure S2 and Table S3). Thus, these data suggest that the binding mechanism of XG to amorphous and crystalline regions of cellulose are similar and morphology plays a limited role in adsorption. ${ }^{17,35-37}$

Collectively, the accessible cellulose surface area (e.g., film thickness), the QCM-D dissipation data, the adsorption isotherms, the water content of adsorbed XG films, and the AFM images suggest a model of XG adsorption onto RC, s$\mathrm{CNC}$, and d-CNC as depicted in Figure 5. For RC films, XG is confined to the surface via nonspecific hydrogen bonding between XG and cellulose. ${ }^{17,36}$ The large water content $(>80 \%$ by mass) of XG films adsorbed onto RC substrates is consistent with a three-dimensional XG conformation in the form of a floppy, loop-and-train-like structure on the RC surface. $^{52}$ This model is consistent with recent work that suggests that as little as $10-15 \%$ XG directly interacts with surface hydroxyl groups. ${ }^{12}$ For s-CNC films, some XG chains are able to penetrate into the porous film. The result is limited sorption of XG into the film and XG adsorption onto the surface. XG sorbed into s-CNC substrates displaces water from the system. Additionally, XG chains within the interior of the porous s-CNC substrate likely bind to multiple nanocrystals, resulting in a more rigid attachment to the cellulose relative to XG chains on the surface only. ${ }^{20}$ Thus, the total water added to the film for XG adsorption onto s-CNC substrates was lower ( $\sim 50 \%$ by mass) than that for XG adsorbed onto RC films. For d-CNC films, XG adsorption was qualitatively similar to adsorption onto s-CNC films. Quantitatively, XG was able to penetrate more deeply into the d-CNC films. As discussed above, the d-CNC pores are likely to be larger than those of the s-CNC film, leading to greater sorption. As QCM-D data indicated a negative change in dissipation for XG adsorption onto d-CNC at low XG concentrations, the presence of $\mathrm{XG}$ within the d-CNC substrate led to a significant decrease in the viscous nature of the total system (d-CNC plus adsorbed XG). However, it is not clear whether this decrease is due to removal of water from the porous d-CNC film, enhanced tethering of various nanocrystals via $\mathrm{XG}$, or both. However, it is likely that the XG primarily acts as a filler between the nanocrystals, rather than a tether, as again, studies have shown that relatively little XG directly contacts the hydroxyl groups of the cellulose surface. $^{12}$ At high XG concentration, limited sorption of XG into the d-CNC film continued, followed by XG adsorption onto the surface. The total water content for XG adsorbed onto d-CNC substrates ( 40\%) was slightly smaller than for $\mathrm{XG}$ adsorbed onto s-CNC substrates, again suggesting that the charge of the cellulose substrate played a limited role on the adsorption process other than to restrict access to the film interior through smaller effective pore sizes.

\section{CONCLUSIONS}

We have shown in this study that cellulose morphology and surface charge have limited effects on the adsorption of XG onto thin films of cellulose, whereas film thickness affects the measured XG adsorption for thinner films of cellulose nanocrystals. Clearly, the accessible surface area (as assessed by varying the film thickness of the porous substrates) of a film plays a significant role in adsorption and must be addressed for future studies between cellulose and other polysaccharides. As XG binding to model cellulose thin films appears nonspecific and uninfluenced by crystallinity of the cellulose sample, RC films have significant advantages over nanocrystalline films in competitive adsorption studies because the adsorbates are confined to the smooth surface of the RC substrate and adsorption onto RC is thus thickness independent. Additionally, the fact that XG penetrates more deeply into the thin $\mathrm{d}$ CNC films has important implications in building nanoscale models of the cell wall and biomimetic composites. One envisions using porous $\mathrm{d}-\mathrm{CNC}$ substrates along with $\mathrm{XG}$, other hemicelluloses, and pectins as a construct for multicomponent primary cell wall models.

\section{METHODS}

Materials. XG from tamarind seeds was purchased from Megazyme, Inc. (202 kDa [lot 00401b]; 31\% xylose, 49\% glucose, $17 \%$ galactose, $2 \%$ arabinose, and $1 \%$ other sugars). Trimethylsilyl cellulose (TMSC) with a degree of substitution of 2.71 was synthesized according to a previous report. ${ }^{53} \mathrm{~s}$ $\mathrm{CNC}$ was prepared by sulfuric acid hydrolysis of dissolvinggrade softwood pulp (Temalfa 93-A-A, Tembec, Inc.), whereas $\mathrm{d}-\mathrm{CNC}$ was prepared by pyridine-based desulfation of sCNC. $^{31}$ Both s-CNC and d-CNC had heights and lengths of 3 \pm 2 and $125 \pm 36 \mathrm{~nm}$, respectively. The charge density of s$\mathrm{CNC}$ was 0.340 mequiv $\cdot \mathrm{g}^{-1}$ as determined by conductometric titration, whereas that of $\mathrm{d}$-CNC was 0.000 mequiv. $\mathrm{g}^{-1} \cdot 11$ Amino-1-undecanethiol, $\mathrm{NH}_{4} \mathrm{OH}(28 \% \mathrm{w} / \mathrm{w})$, and $\mathrm{H}_{2} \mathrm{O}_{2}(30 \%$ $\mathrm{w} / \mathrm{w})$ were purchased from VWR International, Fisher Scientific, and EM Science, respectively. Ultrapure water (Milli-Q Gradient A-10, Milli-Q $18.2 \mathrm{M} \Omega \cdot \mathrm{cm},<5 \mathrm{ppb}$ organic impurities) was used in all experiments.

Substrate Cleaning. Gold QCM-D (Q-Sense AB, gold, 5 $\mathrm{MHz}$ ) and SPR (Reichert, gold) sensors were cleaned by first exposing the surface to $\mathrm{UV} /$ ozone for $20 \mathrm{~min}$, followed by immersion into a $1: 1: 5 \mathrm{v} / \mathrm{v}$ of $\mathrm{NH}_{4} \mathrm{OH} / \mathrm{H}_{2} \mathrm{O}_{2} / \mathrm{H}_{2} \mathrm{O}$ solution at $80{ }^{\circ} \mathrm{C}$ for $1 \mathrm{~h}$. Following another UV/ozone treatment, the substrates were rinsed with water and dried with $\mathrm{N}_{2}$.

Film Deposition. Regenerated Cellulose. RC films were formed on cleaned sensors from a solution of TMSC in toluene spin-coated at $2000 \mathrm{rpm}$ for $60 \mathrm{~s}$. Films of different thickness were obtained by variation of the TMSC solution concentration between 0.2 and $1.0 \%$ by mass. Exposure of the TMSC film to the vapor of an aqueous $10 \%$ by mass solution of hydrochloric acid for 2 min yielded a smooth RC film. ${ }^{28}$ Previous studies have shown that these thin RC films contain $35 \%$ water by mass. ${ }^{32}$

Cellulose Nanocrystals. An amine-terminated alkanethiol self-assembled monolayer $\left(\mathrm{SAM}-\mathrm{NH}_{2}\right)$ was formed on the cleaned gold QCM-D sensor crystals after immersion in a 1 $\mathrm{mM}$ solution of 11-amino-1-undecanol in ethanol for $24 \mathrm{~h}$. Films of different thickness were spin-coated at $4000 \mathrm{rpm}$ for $60 \mathrm{~s}$ from aqueous s-CNC and d-CNC suspensions with concentrations that ranged from 0.2 to $1.0 \%$ by mass. Films were subsequently heat treated overnight at $80{ }^{\circ} \mathrm{C}$ before thicknesses were determined. Previous studies have shown that these thin CNC films contain $76 \%$ water by mass. ${ }^{32}$

Ellipsometry Measurements. The film thickness of the prepared cellulose substrates was determined with a multiangle of incidence ellipsometer (Picometer Ellipsometer, Beaglehole Instruments) equipped with a single wavelength $(633 \mathrm{~nm})$ laser light source. The angle of incidence was varied between 60 and $80^{\circ}$ with $1^{\circ}$ steps. The film thickness was modeled with TFCompanion software (Semiconsoft) assuming a refractive index of 1.51 for RC, s-CNC, and d-CNC films. Further details on the selection of this value for the refractive index for all three types of cellulose films despite variations in their 
morphology can be found in the literature. ${ }^{33,54}$ Each substrate was measured three times, and reported values are average film thicknesses \pm one standard deviation.

Atomic Force Microscopy (AFM) Measurements. Cellulose surfaces were imaged in tapping mode with an Asylum Research AFM (MFP-3D-BIO, Asylum Research). Height images were collected under ambient conditions with a silicon tip (OMCL-AC160TS, Olympus Corp.). The reported root mean square (RMS) roughnesses were determined from 2 $\times 2 \mu \mathrm{m}^{2}$ scan areas. Line scan analysis of aggregates visible on the AFM height images were conducted by obtaining a height profile in the $z$-dimension for ten aggregates. Reported aggregate heights represent the average \pm one standard deviation.

Refractive Index Increment Measurements. The refractive index increment $(\mathrm{d} n / \mathrm{d} c)$ of XG solutions in water was determined with a refractive index detector (Optilab rEX, Wyatt Technology Corp.) equipped with a laser light source $(690 \mathrm{~nm})$. Measurements were conducted at $25{ }^{\circ} \mathrm{C}$ on XG concentrations ranging from 0 to $500 \mathrm{mg} \cdot \mathrm{L}^{-1}$. The $(\mathrm{d} n / \mathrm{d} c)$ was determined from the slope of a plot of refractive index versus concentration.

SPR Measurements. XG adsorption onto cellulose thin films was followed by SPR (SR7000, Reichert Inc.). After the thickness of the cellulose film had been determined by ellipsometry, the sensor slide was immediately placed into the SPR flow cell. Water was introduced into the flow cell at a rate of $0.200 \mathrm{~mL} \cdot \mathrm{min}^{-1}$ at $25^{\circ} \mathrm{C}$ for several hours until a stable baseline was obtained. Degassed XG solution at the same temperature and flow rate as water was then pumped into the flow cell via a switch value, thereby limiting air bubbles in the system. Separate SPR experiments were run for each XG concentration and each cellulose film was exposed to XG for 2 h. Experiments were run in triplicate, and reported values are means \pm one standard deviation. Changes in surface plasmon angle $\left(\theta_{\mathrm{sp}}\right)$ were converted to surface concentration $\left(\Gamma_{\mathrm{SPR}}, \mathrm{mg}\right.$. $\mathrm{m}^{-2}$ ) with the equation of de Feijter et al. ${ }^{46}$ Further information on this equation, as well as details for the calculation of $\Gamma_{\text {SPR }}$ from SPR data, is provided in the Supporting Information.

QCM-D Measurements. An E4 QCM-D (Q-Sense AB) was used to determine $\mathrm{XG}$ adsorption onto cellulose thin films. After the thickness of the cellulose film had been determined by ellipsometry, the sensor crystal was immediately placed into the QCM-D flow cell. Water was introduced into the flow cell at a rate of $0.200 \mathrm{~mL} \cdot \mathrm{min}^{-1}$ at $25{ }^{\circ} \mathrm{C}$ for several hours until a stable baseline was obtained. XG solution was then introduced into the flow cell at the same rate and temperature as water and the change in frequency and dissipation was recorded. Separate QCM-D experiments were run for each XG concentration and each cellulose film was exposed to XG for $2 \mathrm{~h}$. Experiments were run in triplicate, and reported values are means \pm one standard deviation. Changes in measured scaled frequency $(\Delta f / n)$ were converted to surface concentration $\left(\Gamma_{\mathrm{QCM}}, \mathrm{mg}\right.$. $\mathrm{m}^{-2}$ ) with the Sauerbrey equation. ${ }^{45}$ The fifth overtone was used in analyzing all the QCM-D data. Further information on the validity of this equation, as well as details for the calculation of $\Gamma_{\text {QCM }}$ from QCM-D data, is provided in the Supporting Information. In comparing $\Gamma_{\mathrm{QCM}}$ to $\Gamma_{\mathrm{SPR}}$ data, differences arising from flow cell geometry were neglected. ${ }^{51,55}$

\section{ASSOCIATED CONTENT}

\section{Supporting Information}

The Supporting Information is available free of charge on the ACS Publications website at DOI: 10.1021/acsomega.8b01750.

Representative data for xyloglucan adsorption onto cellulose surfaces, determination of surface concentration from QCM-D and SPR data, adsorption isotherm fitting parameters, and roughness and aggregate heights of model surfaces (PDF)

\section{AUTHOR INFORMATION}

\section{Corresponding Author}

*E-mail: joshua.kittle@usafa.edu.

ORCID

Joshua D. Kittle: 0000-0002-7920-2814

Notes

The authors declare no competing financial interest.

\section{ACKNOWLEDGMENTS}

J.D.K., C.Q., and A.R.E. were supported in part by the Center for LignoCellulose Structure and Formation, an Energy Frontier Research Center funded by the U.S. Department of Energy, Office of Science, Office of Basic Energy Sciences under Award Number DE-SC0001090. The project was also partially supported by the National Science Foundation (CHE0724126) and the Southeastern Sun Grant Center with funds provided by the U.S. Department of Energy, Office of the Biomass Program.

\section{REFERENCES}

(1) Himmel, M. E.; Ding, S.-Y.; Johnson, D. K.; Adney, W. S.; Nimlos, M. R.; Brady, J. W.; Foust, T. D. Biomass Recalcitrance: Engineering Plants and Enzymes for Biofuels Production. Science 2007, 315, 804-807.

(2) Roman, M. History and Recent Advances. In Model Cellulosic Surfaces; Roman, M., Ed.; ACS Symposium Series 1019; American Chemical Society: Washington, DC, 2009; pp 3-53.

(3) Kochumalayil, J.; Sehaqui, H.; Zhou, Q.; Berglund, L. A. Tamarind seed xyloglucan-a thermostable high-performance biopolymer from non-food feedstock. J. Mater. Chem. 2010, 20, 43214327.

(4) Cerclier, C. V.; Guyomard-Lack, A.; Cousin, F.; Jean, B.; Bonnin, E.; Cathala, B.; Moreau, C. Xyloglucan-cellulose nanocrystal multilayered films: effect of film architecture on enzymatic hydrolysis. Biomacromolecules 2013, 14, 3599-3609.

(5) Albersheim, P.; Darvill, A.; Roberts, K.; Sederoff, R.; Staehelin, A. Plant Cell Walls; Garland Science: New York, 2011.

(6) Zabotina, O. A. Xyloglucan and its biosynthesis. Front. Plant Sci. 2012, 3, 134.

(7) Cosgrove, D. J. Growth of the plant cell wall. Nat. Rev. Mol. Cell Biol. 2005, 6, 850-861.

(8) Hayashi, T.; Ogawa, K.; Mitsuishi, Y. Characterization of the adsorption of xyloglucan to cellulose. Plant Cell Physiol. 1994, 35, $1199-1205$.

(9) Hayashi, T. Xyloglucans in the primary cell wall. Annu. Rev. Plant Physiol. Plant Mol. Biol. 1989, 40, 139-168.

(10) Talbott, L. D.; Ray, P. M. Molecular size and separability features of pea cell wall polysaccharides: implications for models of primary wall structure. Plant Physiol. 1992, 98, 357-368.

(11) Thompson, J. E.; Fry, S. C. Evidence for covalent linkage between xyloglucan and acidic pectins in suspension-cultured rose cells. Planta 2000, 211, 275-286. 
(12) Dick-Pérez, M.; Zhang, Y.; Hayes, J.; Salazar, A.; Zabotina, O. A.; Hong, M. Structure and interactions of plant cell-wall polysaccharides by two-and three-dimensional magic-angle-spinning solid-state NMR. Biochemistry 2011, 50, 989-1000.

(13) Bodin, A.; Ahrenstedt, L.; Fink, H.; Brumer, H.; Risberg, B.; Gatenholm, P. Modification of nanocellulose with a xyloglucan-RGD conjugate enhances adhesion and proliferation of endothelial cells: implications for tissue engineering. Biomacromolecules 2007, 8, 36973704.

(14) Vincken, J.-P.; de Keizer, A.; Beldman, G.; Voragen, A. G. J. Fractionation of xyloglucan fragments and their interaction with cellulose. Plant Physiol. 1995, 108, 1579-1585.

(15) Hayashi, T.; Marsden, M. P. F.; Delmer, D. P. Pea xyloglucan and cellulose: VI. Xyloglucan-cellulose interactions in vitro and in vivo. Plant Physiol. 1987, 83, 384-389.

(16) Ahola, S.; Petri, M.; Österberg, M.; Teerinen, T.; Laine, J. Effect of polymer adsorption on cellulose nanofibril water binding capacity and aggregation. BioResources 2008, 3, 1315-1328.

(17) Lopez, M.; Bizot, H.; Chambat, G.; Marais, M.-F.; Zykwinska, A.; Ralet, M.-C.; Driguez, H.; Buléon, A. Enthalpic studies of xyloglucan-cellulose interactions. Biomacromolecules 2010, 11, 14171428.

(18) Cerclier, C.; Cousin, F.; Bizot, H.; Moreau, C.; Cathala, B. Elaboration of spin-coated cellulose-xyloglucan multilayered thin films. Langmuir 2010, 26, 17248-17255.

(19) Lima, D. U.; Loh, W.; Buckeridge, M. S. Xyloglucan-cellulose interaction depends on the sidechains and molecular weight of xyloglucan. Plant Physiol. Biochem. 2004, 42, 389-394.

(20) Benselfelt, T.; Cranston, E. D.; Ondaral, S.; Johansson, E.; Brumer, H.; Rutland, M. W.; Wagberg, L. Adsorption of xyloglucan onto cellulose surfaces of different morphologies: an entropy-driven process. Biomacromolecules 2016, 17, 2801-2811.

(21) Park, Y. B.; Cosgrove, D. J. Xyloglucan and its Interactions with Other Components of the Growing Cell Wall. Plant Cell Physiol. 2015, 56, 180-194.

(22) Chambat, G.; Karmous, M.; Costes, M.; Picard, M.; Joseleau, J. $\mathrm{P}$. Variation of xyloglucan substitution pattern affects the sorption on celluloses with different degrees of crystallinity. Cellulose 2005, 12, 117-125.

(23) Newman, R. H.; Hill, S. J.; Harris, P. J. Wide-angle X-ray scattering and solid-state nuclear magnetic resonance data combined to test models for cellulose microfibrils in mung bean cell walls. Plant Physiol. 2013, 163, 1558-1567.

(24) Villares, A.; Bizot, H.; Moreau, C.; Rolland-Sabate, A.; Cathala, B. Effect of xyloglucan molar mass on its assembly onto the cellulose surface and its enzymatic susceptibility. Carbohydr. Polym. 2017, 157, $1105-1112$.

(25) Villares, A.; Moreau, C.; Dammak, A.; Capron, I.; Cathala, B. Kinetic aspects of the adsorption of xyloglucan onto cellulose nanocrystals. Soft Matter 2015, 11, 6472-6481.

(26) Schaub, M.; Wenz, G.; Wegner, G.; Stein, A.; Klemm, D. Ultrathin films of cellulose on silicon wafers. Adv. Mater. 1993, 5, 919-922.

(27) Kontturi, E.; Thüne, P. C.; Niemantsverdriet, J. W. Cellulose Model Surfaces - Simplified Preparation by Spin Coating and Characterization by X-ray Photoelectron Spectroscopy, Infrared Spectroscopy, and Atomic Force Microscopy. Langmuir 2003, 19, 5735-5741.

(28) Revol, J. F.; Bradford, H.; Giasson, J.; Marchessault, R. H.; Gray, D. G. Helicoidal self-ordering of cellulose microfibrils in aqueous suspension. Int. J. Biol. Macromol. 1992, 14, 170-172.

(29) Jiang, F.; Kittle, J. D.; Tan, X.; Esker, A. R.; Roman, M. Effects of sulfate groups on the adsorption and activity of cellulases on cellulose substrates. Langmuir 2013, 29, 3280-3291.

(30) Jiang, F.; Esker, A. R.; Roman, M. Acid-Catalyzed and Solvolytic Desulfation of $\mathrm{H}_{2} \mathrm{SO}_{4}$-Hydrolyzed Cellulose Nanocrystals. Langmuir 2010, 26, 17919-17925.
(31) Kontturi, E.; Suchy, M.; Penttilä, P.; Jean, B.; Pirkkalainen, K.; Torkkeli, M.; Serimaa, R. Amorphous characteristics of an ultrathin cellulose film. Biomacromolecules 2011, 12, 770-777.

(32) Kittle, J. D.; Du, X.; Jiang, F.; Qian, C.; Heinze, T.; Roman, M.; Esker, A. R. Equilibrium water contents of cellulose films determined via solvent exchange and quartz crystal microbalance with dissipation monitoring. Biomacromolecules 2011, 12, 2881-2887.

(33) Edgar, C. D.; Gray, D. G. Smooth model cellulose I surfaces from nanocrystal suspensions. Cellulose 2003, 10, 299-306.

(34) Aulin, C.; Ahola, S.; Josefsson, P.; Nishino, T.; Hirose, Y.; Österberg, M.; Wågberg, L. Nanoscale Cellulose Films with Different Crystallinities and Mesostructures - Their Surface Properties and Interaction with Water. Langmuir 2009, 25, 7675-7685.

(35) O'Sullivan, A. C. Cellulose: the structure slowly unravels. Cellulose 1997, 4, 173-207.

(36) Hanus, J.; Mazeau, K. The xyloglucan-cellulose assembly at the atomic scale. Biopolymers 2006, 82, 59-73.

(37) Verlhac, C.; Dedier, J.; Chanzy, H. Availability of surface hydroxyl groups in valonia and bacterial cellulose. J. Polym. Sci., Part A: Polym. Chem. 1990, 28, 1171-1177.

(38) Reid, M. S.; Kedzior, S. A.; Villalobos, M.; Cranston, E. D. Effect of Ionic Strength and Surface Charge Density on the Kinetics of Cellulose Nanocrystal Thin Film Swelling. Langmuir 2017, 33, 74037411.

(39) Picout, D. R.; Ross-Murphy, S. B.; Errington, N.; Harding, S. E. Pressure cell assisted solubilization of xyloglucans: Tamarind seed polysaccharide and detarium gum. Biomacromolecules 2003, 4, 799807.

(40) Abuja, P. M.; Schmuck, M.; Pilz, I.; Tomme, P.; Claeyssens, M.; Esterbauer, H. Structural and functional domains of cellobiohydrolase I from Trichoderma reesei: A small angle X-ray scattering study of the intact enzyme and its core. Eur. Biophys. J. 1988, 15, 339-342.

(41) Höök, F.; Kasemo, B.; Nylander, T.; Fant, C.; Sott, K.; Elwing, H. Variations in Coupled Water, Viscoelastic Properties, and Film Thickness of a Mefp-1 Protein Film during Adsorption and CrossLinking: A Quartz Crystal Microbalance with Dissipation Monitoring, Ellipsometry, and Surface Plasmon Resonance Study. Anal. Chem. 2001, 73, 5796-5804.

(42) Teichroeb, J. H.; Forrest, J. A.; Jones, L. W.; Chan, J.; Dalton, K. Quartz crystal microbalance study of protein adsorption kinetics on poly(2-hydroxyethyl methacrylate). J. Colloid Interface Sci. 2008, 325, 157-164.

(43) Lord, M. S.; Stenzel, M. H.; Simmons, A.; Milthorpe, B. K. The effect of charged groups on protein interactions with poly(HEMA) hydrogels. Biomaterials 2006, 27, 567-575.

(44) Kittle, J. D.; Wondraczek, H.; Wang, C.; Jiang, F.; Roman, M.; Heinze, T.; Esker, A. R. Enhanced dewatering of polyelectrolyte nanocomposites by hydrophobic polyelectrolytes. Langmuir 2012, 28, 11086-11094.

(45) Sauerbrey, G. Verwendung von Schwingquarzen zur Wägung dünner Schichten und zur Mikrowägung. Z. Phys. 1959, 155, 206222.

(46) de Feijter, J. A.; Benjamins, J.; Veer, F. A. Ellipsometry as a tool to study the adsorption behavior of synthetic and biopolymers at the air-water interface. Biopolymers 1978, 17, 1759-1722.

(47) Kaya, A.; Du, X.; Liu, Z.; Lu, J. W.; Morris, J. R.; Glasser, W. G.; Heinze, T.; Esker, A. R. Surface plasmon resonance studies of pullulan and pullulan cinnamate adsorption onto cellulose. Biomacromolecules 2009, 10, 2451-2459.

(48) Kanazawa, K. K.; Gordon, J. G. Frequency of a quartz microbalance in contact with liquid. Anal. Chem. 1985, 57, 17701771.

(49) Hedin, J.; Löfroth, J.-E.; Nydén, M. Adsorption behavior and cross-linking of EHEC and HM-EHEC at hydrophilic and hydrophobic modified surfaces monitored by SPR and QCM-D. Langmuir 2007, 23, 6148-6155.

(50) Orelma, H.; Filpponen, I.; Johansson, L.-S.; Laine, J.; Roja, O. J. Modification of Cellulose Films by Adsorption of CMC and Chitosan 
for Controlled Attachment of Biomolecules. Biomacromolecules 2011, 12, 4311-4318.

(51) Reid, M. S.; Villalobos, M.; Cranston, E. D. Cellulose nanocrystal interactions probed by thin film swelling to predict dispersibility. Nanoscale 2016, 8, 12247.

(52) Villares, A.; Bizot, H.; Moreau, C.; Rolland-Sabate, A.; Cathala, B. Effect of xyloglucan molar mass on its assembly onto the cellulose surface and its enzymatic susceptibility. Carbohydr. Polym. 2017, 157, $1105-1112$.

(53) Rivera-Armenta, J. L.; Heinze, T.; Mendoza-Martínez, A. M. New polyurethane foams modified with cellulose derivatives. Eur. Polym. J. 2004, 40, 2803-2812.

(54) Karabiyik, U.; Mao, M.; Roman, M.; Jaworek, T.; Wegner, G.; Esker, A. R. Optical Characterization of Cellulose Films via Multiple Incident Media Ellipsometry. In Model Cellulosic Surfaces; Roman, M., Ed.; ACS Symposium Series 1019; American Chemical Society: Washington, DC, 2009; pp 137-155.

(55) Viitala, T.; Liang, H.; Gupta, M.; Zwinger, T.; Yliperttula, M.; Bunker, A. Fluid dynamics modeling for synchronizing surface plasmon resonance and quartz crystal microbalance as tools for biomolecular and targeted drug delivery studies. J. Colloid Interface Sci. 2012, 378, 251-259. 